Article

\title{
The Impact of Process Factors on Creating Defects, Mainly Lustrous Carbon, during the Production of Ductile Iron Using the Lost-Foam Casting (LFC) Method
}

\author{
Jan Jezierski ${ }^{1, * \mathbb{C}}$, Michał Jureczko ${ }^{1,2}$ and Rafał Dojka ${ }^{1,2}$ (D) \\ 1 Department of Foundry Engineering, Silesian University of Technology, 44-100 Gliwice, Poland; \\ m.jureczko@odlewnia-rafamet.pl (M.J.); r.dojka@odlewnia-rafamet.pl (R.D.) \\ 2 Odlewnia RAFAMET Sp. z o.o., 47-420 Kuźnia Raciborska, Poland \\ * Correspondence: jan.jezierski@polsl.pl; Tel.: +48-32-338-5551
}

Received: 25 June 2020; Accepted: 23 July 2020; Published: 30 July 2020

check for updates

\begin{abstract}
The purpose of this paper was to analyze the process factors affecting the occurrence of lustrous carbon defects in ductile cast iron castings when using the lost-foam casting (LFC) method. This phenomenon results in creating raw surface defects, which sometimes may even lead to cast iron scrapping. A series of trial melting batches were carried out for variable process assumptions. The analysis was performed to reflect, to the greatest extent possible, real foundry production conditions. Industrial tests were performed in Odlewnia Rafamet Sp. z o.o., Kuźnia Raciborska, Poland. The polystyrene patterns created by gluing components together, used in the tests, met the requirements of the high-tech lost-foam casting (LFC) process. The performed analysis allowed the obtaining of lustrous carbon defects in test castings as well as the determination of the process parameters with the highest impact on lustrous carbon inclusions in ductile iron castings. The test results were used to eliminate the possibility of creating a defect and thus directly improve the efficiency of the lost-foam casting (LFC) process used in the foundry.
\end{abstract}

Keywords: lustrous carbon; lost foam casting; full mold method; ductile cast iron; casting defects

\section{Introduction}

The lost foam casting (LFC) process has been known globally since 1958 when Shroyer published his patent [1], where he described the use of a Styrofoam pattern reflecting the shape of the casting. The method is also referred to as "Full Mold", which emphasizes pouring a mold without removing the casting, which is subject to gasification with the heat of a hot alloy filling the mold [2]. At first, the Styrofoam patterns featured a low dimensional-shape accuracy and a considerable roughness of the casting surfaces. A significant increase in the interest in the lost-foam casting (LFC) method was observed in the late 1980s. Then, thanks to the use of modern production technologies, e.g., CNC machine tools and laser cutting, Styrofoam patterns featured higher accuracy than in the earlier years [3].

Ductile cast iron is a very important material for processes, widely used in the automotive and machine-building industries. Year by year, the production of ductile cast iron increases dynamically, which is stimulated by higher demand for cast iron with nodular graphite [4]. The defects that occur in the casting process frequently play a crucial role in restricting the mechanical properties and fatigue life under cyclic load of cast items. Casting defects associated with lustrous carbon are treated as inclusions. However, it must be kept in mind that they always show a double nature, and thus, based on the theories of Prof. Campbell, they should also be treated as bifilms [5]. In a typical process, using an 
extracted pattern, plenty of air is present in the mold during filling and oxide bifilms are likely to appear. However, in the lost-foam and full mold processes, the volume normally occupied by air is initially filled with Styrofoam, and air can only be present in the volume of the mold. The flowing stream of metal causes gasification of the Styrofoam, resulting in the formation of a carbon-rich gas environment with accompanying ashes and possibly portions of air from the mold [6,7]. This phenomenon can result in the formation of a thin oxide layer on the advancing metal front, followed by the deposition of a relatively thick carbon layer. The occurrence of turbulence in the mold that allows the formation of breaking waves causes the entrainment of double carbon films in the melt. If the manufactured castings weigh many tons, as is the case of Odlewnia Rafamet, then if any defects and incompatibilities occur, the economic viability of repairing the castings is estimated. When the decision to repair is made, the most frequently selected method for repair is one of the welding methods; however, it involves some process difficulties. The goal is to eliminate any imperfections from castings, which is not easy [8]. Therefore, every effort should be made to achieve the highest possible surface quality for raw castings. One of the typical defects of ductile cast iron surfaces includes lustrous carbon inclusions that considerably compromise their properties [9]. Such carbon defects begin to occur when the liquid metal is poured into the mold cavity, which results in thermal degradation and/or forces the polystyrene pattern to emit hydrocarbon gases. The products of the thermal decomposition of the Styrofoam pattern exit through the refractory coating and sand to the outside of the mold $[10,11]$. The defect in the form of lustrous carbon occurs when the molding compounds used to fill the mold with liquid metal generate large amounts of carbon material decomposition products (i.e., lustrous carbon carriers). This defect appears in castings in the form of areas with wrinkled, lustrous surfaces that frequently look like cold laps, folds, or rattails; see Figure 1. The wrinkled or ground surfaces are frequently referred to as elephant skin, alligator skin, or crow's feet. However, we should distinguish between the elephant skin defect, resulting from lustrous carbon inclusions, and a similar defect, resulting from the inclusions of spheroidization residue products, especially magnesium master alloy after adding an excessively large portion of it, as well as the so-called bifilm defects [12].

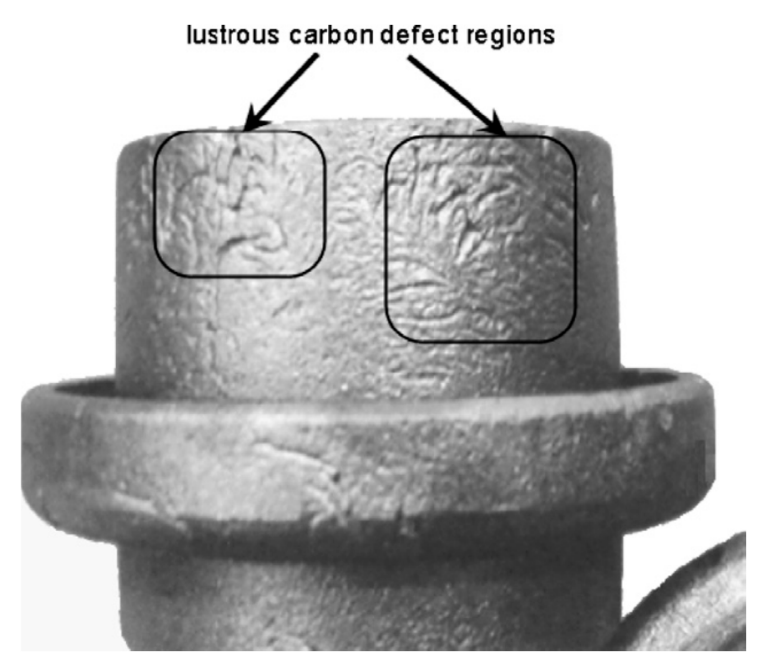

Figure 1. The defect of the casting surface generated in the lost-foam casting (LFC) process caused by lustrous carbon inclusions [9].

The studies covering lustrous carbon generation show that factors such as pouring time and pouring process have a significant impact on the occurrence of the above-mentioned defect in castings. The studies have shown that turbulent mold filling and an improperly selected temperature stimulate the generation of the defects $[13,14]$. Moreover, some experiments have focused on the sand properties affecting the structure and the properties of castings, for example, aluminum casting, as shown in [15]. 
Quite frequently, the lustrous carbon is confused with resin residues or soot. This is caused by the fact that the defect occurs very often when a traditional molding compound is bonded with chemical binders [16,17].

Currently, the lustrous carbon is considered to be one of the main defects of the lost-foam casting (LFC) process. The studies performed by the American Foundry Society, described in [14], allowed the definition of how the casting wall thickness affects the occurrence of the defect. It turned out that thicker wall castings were less susceptible to lustrous carbon defects.

\section{Materials and Methods}

The motivation behind the studies was quality issues detected in a foundry that manufactured heavy castings and used the lost-foam casting (LFC) process with some in-house modifications. As a result, the first stage of the conducted studies was to design a pattern to meet the requirements and limitations resulting from the manufacturing process used by the Rafamet foundry. Figure 2 presents the shape and dimensions of a foamed polystyrene pattern used in the experiments.
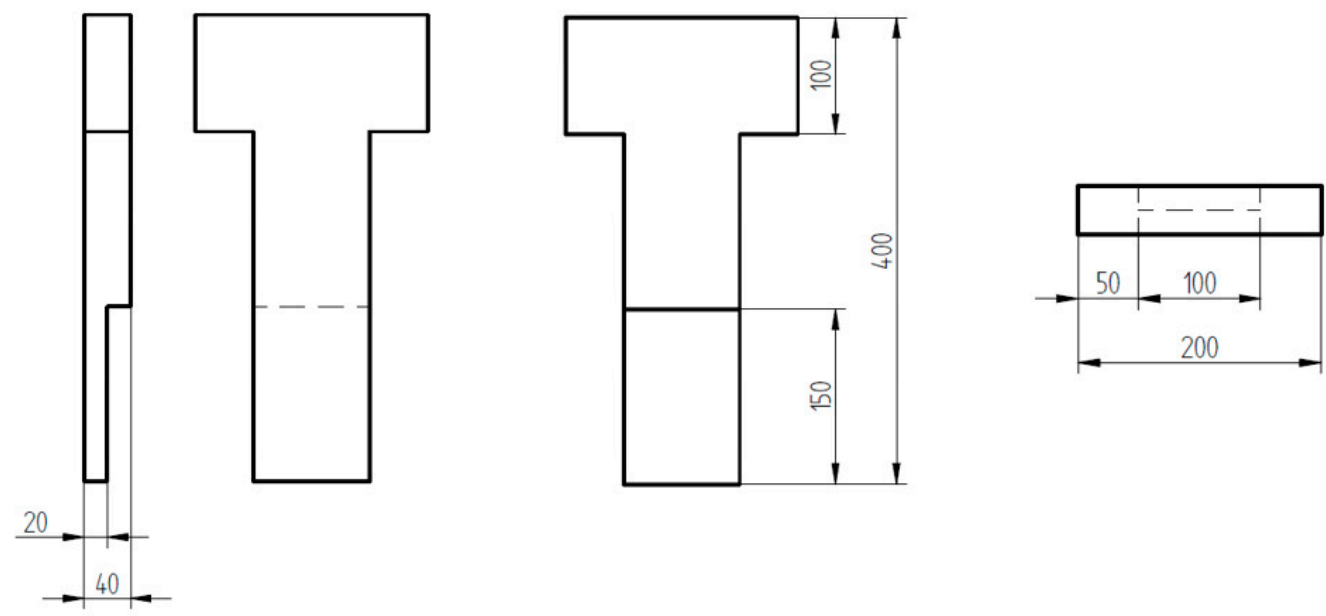

Figure 2. Molding pattern used in the tests (unit: $\mathrm{mm}$ ).

Polymers used to produce mold patterns have to meet many criteria. They should be relatively easy to shape and, at the same time, show some desired physical and chemical properties. First of all, they should provide a pattern with adequate strength during shaping [18]. Additionally, the process of pattern gasification should be rapid and as complete as possible, without excessive, solid combustion products. The transition of the polystyrene pattern from solid to the gaseous state, as a result of the thermal effect of the liquid metal filling the mold cavity, is a very complex process [19].

The casting pattern used during the studies was intentionally provided with building imperfections to stimulate the generation of defects. Among other things, all the walls were designed without any curvature radii. Besides, some pattern areas were seriously affected by the generation of thermal nodes. Those places allowed us to further analyze contraction cavities for variable process parameters. Studies were performed under the industrial conditions of the Rafamet foundry during normal production. As a result, the experiments were partially passive, i.e., some parameters, e.g., temperature, were not preset without any restraints. They were measured only for the assumed fluctuation levels.

The studies consisted of four melt series with 16 sample castings in total obtained. Each melting was preceded by several pattern preparation steps and the actual forming process. Each melt was analyzed for variable parameters related to process assumptions, chemical composition, molding compound sand grains, pouring temperature, and refractory coating. These were likely to stimulate the generation of lustrous carbon inclusions. Because of the necessity to keep the foundry know-how secret, the ranges of most of the fluctuations are not quoted. 


\subsection{The Parameters Analyzed during the First Series of Melts}

\subsubsection{Molding Sand Matrix}

The molds were made of two compound types: facing and filling sand. The facing sand consisted of two sand types: quartz and synthetic sand. It was used only to cover the pattern face surfaces, the ones with a gradual wall thickness change. This is the surface that is the part that was compared to other samples during the studies. The remaining surfaces were filled with quartz-based grain sand at a ratio of $90 \%$ reclaim and $10 \%$ fresh sand. The correct use of materials applied in the molding and core compounds has a significant impact on the quality of the molds and castings, at the same time reducing the number of defective castings [20]. The purpose of the analysis was to determine the impact of sand grain on gas permeability. At the same time, the quality of the surface was tested, as this parameter could frequently have a decisive effect.

\subsubsection{Pouring Temperature}

The actual pouring temperature for the first series of sample castings was $1305^{\circ} \mathrm{C}$. The temperature value was determined at the same level to estimate its variation range for further experiments. It was estimated based on the foundry's experience and by comparison with the process conditions for production and sample castings. Once the first samples were obtained and after completing the estimation of the temperature's effect on lustrous carbon inclusions and on the quality of castings, the pouring temperatures of the subsequent samples were determined.

\subsubsection{Casting Alloy Used}

Melting casting alloys is one of the most energy-consuming casting processes, which accounts for the prevailing part of the casting production costs. Additionally, the ductile cast iron is complex in terms of process features and is susceptible to various defects, including lustrous carbon inclusions.

The first samples were poured using EN GJS 400-15 ductile cast iron. The pouring temperature value of this alloy, after analyzing the first series of melt results, became the initial alloy parameter for subsequent tests.

\subsubsection{Molding Pattern}

The analysis covered the density of material per pattern and pattern layout in the molding flask. Two patterns were arranged in such a way that the molds were fed from the bottom wall, while the subsequent two molds made it possible for them to be filled from their upper wall.

\subsection{The Parameters Analyzed during the Second Series of Melts}

\subsubsection{Connection between Pattern Fragments}

Two types of adhesives were used to bond the pattern fragments. They featured different set times and bonding strengths.

\subsubsection{Chemical Composition of Casting Alloy}

An additional portion of carburizer was added to the liquid alloy to increase its carbon level.

\subsubsection{Pouring Temperature}

The temperature for filling the mold, in this case, was $1236^{\circ} \mathrm{C}$. This value is slightly below the recommended pouring temperature, which is often stated as $1350{ }^{\circ} \mathrm{C}$. The reason for this was to define the impact of low temperature both on lustrous carbon inclusions and on the quality of the surface obtained. Using different temperatures allowed us to estimate how this parameter affected the 
occurrence of undesired inclusions. Additionally, it made it possible to observe the impact of alloy flowing power on the capacity to fill the mold.

\subsection{The Parameters Analyzed during the Third Series of Melts}

\subsubsection{Pouring Temperature}

The cast iron temperature used to fill these samples was $1360^{\circ} \mathrm{C}$. That was the highest liquid alloy temperature used during the studies performed.

\subsubsection{Molding Sand}

During this series of melts, quartz sand-based molding sand was used. The grain sand consisted of reclaim, and the reason for this approach was to check how the low-quality molding compound (cheap molding compound) affected the defect generation process. One of the advantages of the compound process using the furfuryl alcohol resin (furan resin) used in the tests was its application versatility and the properties of the molding compound.

\subsection{The Parameters Analyzed during the Fourth Series of Melts}

\subsubsection{Refractory Coating}

The layer of refractory coating should feature high permeability to allow gases generated inside the mold to easily exit the cavity. At the same time, it should be compact and fireproof enough to provide the proper quality of the raw casting surface.

Two different types of coating were used, maintaining the same application method, i.e., painting patterns with a brush. Two different coatings-the first, water solvent graphite-based-were used for the majority of the samples. For contrast, two samples were covered with alcohol solvent zirconia-based coating. The latter coating is used by the Rafamet foundry for polystyrene patterns in places with increased risks of burns.

\subsubsection{Pouring Temperature}

The samples from this series were filled with liquid material at a temperature of $1250^{\circ} \mathrm{C}$.

\subsubsection{Chemical Composition}

A decision was made to increase the carbon level by adding a crushed carburizer into the inlet container. The chemical composition should feature a high carbon level to increase the risk of the occurrence of defects and imperfections under analysis.

\section{Results}

The results of particular melt series are presented below in sequence. Photos of sample melts are presented with the areas of the defects under analysis marked in Figures 3-7. 

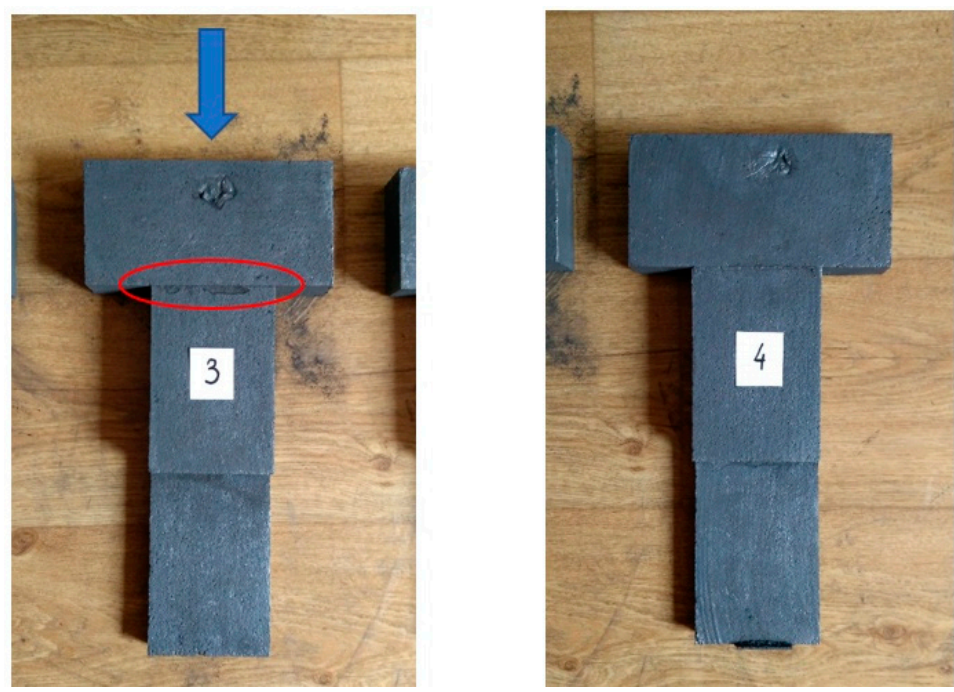

Figure 3. Sample castings. The defects related to pattern craftsmanship are marked red, while the inlet system entrance and pouring direction are marked blue; Melt 1.

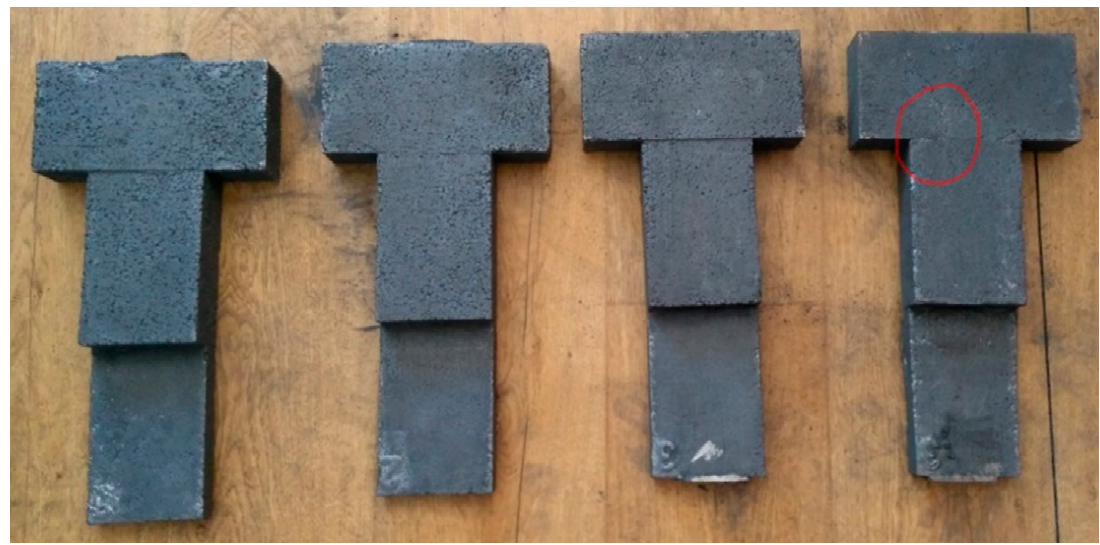

Figure 4. View of castings after removing the inlet system with a marked defect in the form of a lustrous carbon inclusion; Melt 2.

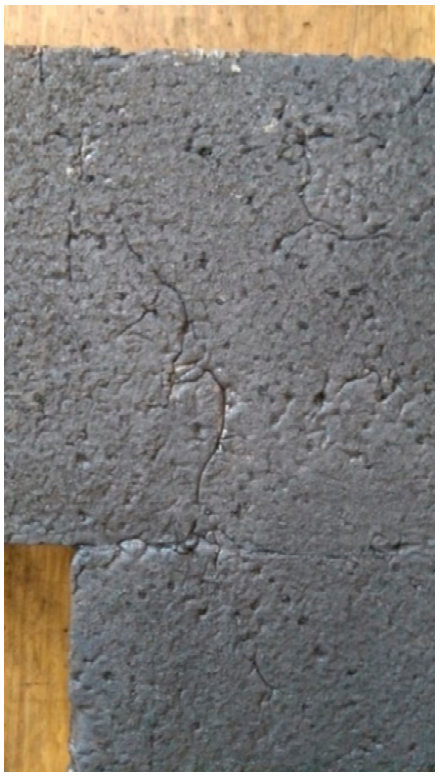

Figure 5. A blown-up image of the lustrous carbon inclusion; Melt 2. 


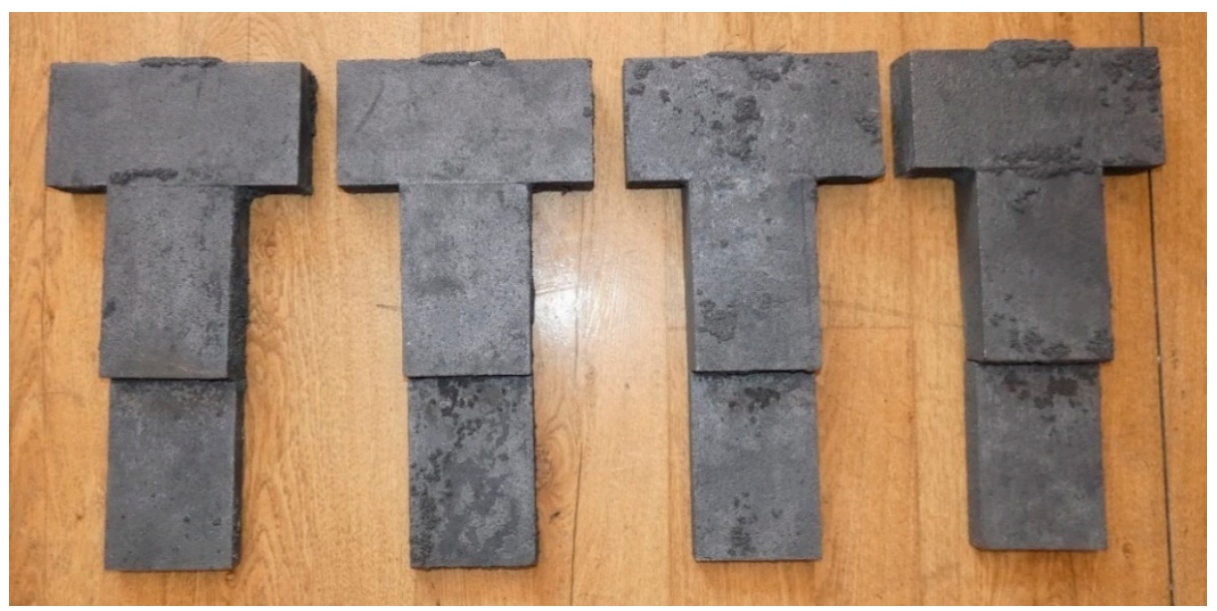

Figure 6. View of castings after removing the inlet system, Melt 3.

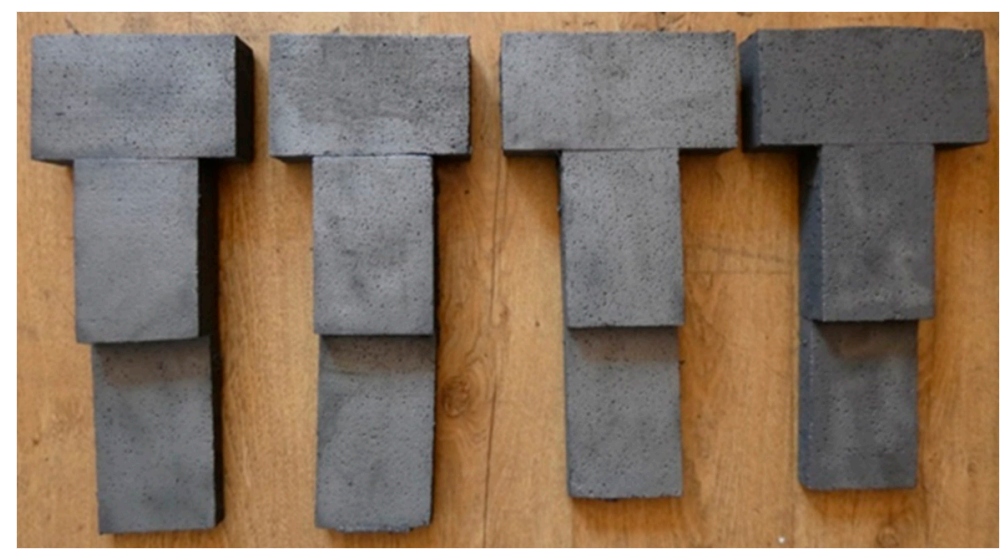

Figure 7. View of castings after removing the inlet system; Melt 4.

\subsection{Melt 1}

In Tables 1-4, the carbon equivalent CE and eutectic saturation factor Sc were calculated as per the formulas given below:

$$
\begin{gathered}
\mathrm{CE}=4.26-0.31 \mathrm{Si}-0.33 \mathrm{P}+0.027 \mathrm{Mn}-0.40 \mathrm{~S} \\
\mathrm{Sc}=\mathrm{C} /(4.26-0.31 \mathrm{Si}-0.33 \mathrm{P})
\end{gathered}
$$

Table 1. The chemical composition of the cast iron obtained in Melt 1; wt $\%$.

\begin{tabular}{ccccccccc}
\hline DI Grade & C & Si & Mn & S & P & Mg & CE & Sc \\
\hline EN-GJS 400-15 & 3.69 & 2.29 & 0.16 & 0.006 & 0.046 & 0.054 & 4.407 & 1.041 \\
\hline
\end{tabular}

Table 2. The chemical composition of cast iron obtained in Melt 2; wt $\%$.

\begin{tabular}{ccccccccc}
\hline DI Grade & C & Si & Mn & S & P & Mg & CE & Sc \\
\hline EN-GJS 400-15 & 3.41 & 2.04 & 0.18 & 0.008 & 0.046 & 0.035 & 4.06 & 0.945 \\
\hline
\end{tabular}

Table 3. The chemical composition of cast iron obtained in Melt 3; wt $\%$.

\begin{tabular}{ccccccccc}
\hline DI Grade & $\mathbf{C}$ & $\mathbf{S i}$ & $\mathbf{M n}$ & $\mathbf{S}$ & $\mathbf{P}$ & $\mathbf{M g}$ & $\mathbf{C E}$ & Sc \\
\hline EN-GJS 700-2 & 3.41 & 2.57 & 0.47 & 0.010 & 0.052 & 0.053 & 4.215 & 0.987 \\
\hline
\end{tabular}


Table 4. The chemical composition of cast iron obtained in Melt 4; wt \%.

\begin{tabular}{ccccccccc}
\hline DI grade & $\mathbf{C}$ & Si & Mn & S & P & Mg & CE & Sc \\
\hline EN-GJS 400-15 & 3.43 & 2.30 & 0.20 & 0.013 & 0.081 & 0.053 & 4.175 & 0.976 \\
\hline
\end{tabular}

The defects generated on all four samples were caused by the improper selection of the casting number attachment place. This step was carried out by a blue-collar worker who was not aware that the defect could have occurred. In this case, that was a contraction defect showing different features, depending on the grain sand used. Castings 1 and 2, molded with quartz sand, show slightly different defects from Castings 3 and 4. It is mainly about the size and depth of the contraction cavities generated. The samples molded with quartz sand show slightly larger defects than the remaining two samples. By contrast, Castings 3 and 4 show less extended but slightly deeper defects. Those discontinuities may have been affected by the pouring temperature. The temperature of $1305^{\circ} \mathrm{C}$ is lower than the optimum temperature for pouring ductile cast iron. This parameter may have affected the flowing power and the capacity to fill the mold.

The defects marked red are related to the direction of pattern pouring. This defect appeared when the metal was fed as shown by the arrows on the photos above. The two remaining samples did not show the defect because they were poured from the other side. This relates to the method of pattern creation. This is because it is manufactured with three parts bonded with a polymer adhesive. In places of defect occurrence, the pattern is glued; therefore, it can lead to the dislocation or tearing of some parts of the pattern. This tear-off may have also occurred during pattern shaping. The weight of the molding compound may have broken off a piece of the pattern from the complete body. The problem is hard to assess because the foundry is not provided with instruments to analyze the reason behind the quality issue.

\subsection{Melt 2}

The quality of the casting surfaces in places where the casting numbers were glued on significantly deviates from the quality of the remaining castings. Those markings had an extremely negative impact on the quality of the surface obtained. The quality of the sidewalls for all the castings differs significantly from the desired casting quality level.

As compared to melt No. 1, the samples look worse. The obtained castings show a lower level of carbon and silicon, as compared to the previous ones. Carbon and silicon are two basic elements that have a huge impact on the crystallization and the final casting structure-shaping process. The amount of carbon is slightly below the recommended value for the production of this cast iron grade in the Rafamet foundry. Reducing the amount of carbon in the chemical composition provides hypo-eutectic cast iron. An elevated concentration of silicon in the cast iron increases the amount of graphite in its structure. For both Melts 1 and 2, the amount of silicon in their chemical compositions is within the range for the recommended concentration for this element in the final chemical composition.

The defect of the lustrous carbon inclusion presented in Figure 6 may result from a pouring temperature that, in this particular case, was $1236^{\circ} \mathrm{C}$. Reducing this value by about $100{ }^{\circ} \mathrm{C}$ from the recommended temperature significantly reduces the efficiency of the mold cavity filling process. This is because it has a considerable impact on the alloy flowing power. All those dependencies translate into the quality of the castings. The side edges do not accurately reflect the polystyrene pattern, which considerably reduces the quality of the castings obtained. Besides, the potential of lustrous carbon inclusion generation increases significantly.

The use of two different types of adhesive did not affect the quality of the castings obtained. All samples met the requirements without any reservations. As a result, the adhesive from a cheaper manufacturer was chosen optionally for further studies for budgetary reasons, maintaining the quality parameters at an unchanged level. 


\subsection{Melt 3}

The castings during the third melt series did not show any contraction-related defects. Adopting a fundamentally bad pattern, with a large module in the central part, did not stimulate any occurrence of lustrous carbon inclusions. The numerous burns of the molding compound found on the surface of each casting can be related to two parameters. The first one is the pouring temperature, which was selected above the recommended level, which resulted in the appearance of thermal-origin defects. The second parameter is the concentration of the reclaimed part in the molding compound. The combination of the two unfavorable parameters causes many problems. The use of a compound with a reclaim level of $100 \%$ showed that such a step provides benefits, as there was no need to use any fresh sand. However, it induces some unfavorable effects. The use of such compounds results in many defects to be removed. Their removal requires a lot of time and money. The cost of repairing castings that were molded with such a compound is frequently higher than the profits resulting from the use of a fully reclaimed molding compound. The temperature of $1360^{\circ} \mathrm{C}$ was the highest pouring temperature used during the performed studies. It can be noticed that values higher than those recommended for pouring have a very low impact on the occurrence of lustrous carbon inclusions. After three melt series, it was found that the reduced temperature was the factor that mainly stimulated the occurrence of that defect. During the final melt series, the pouring temperature was approximately $1250{ }^{\circ} \mathrm{C}$.

\subsection{Melt 4}

The use of coating did not considerably affect the surface quality. All samples look almost the same, but in the corner of one of them, there is a defect in the form of lustrous carbon as presented in Figure 8 . The surfaces of the castings obtained accurately reflected the molding pattern. A low pouring temperature had a lower effect on the quality of the samples obtained, as compared to the that of the melts of batch No. 2.

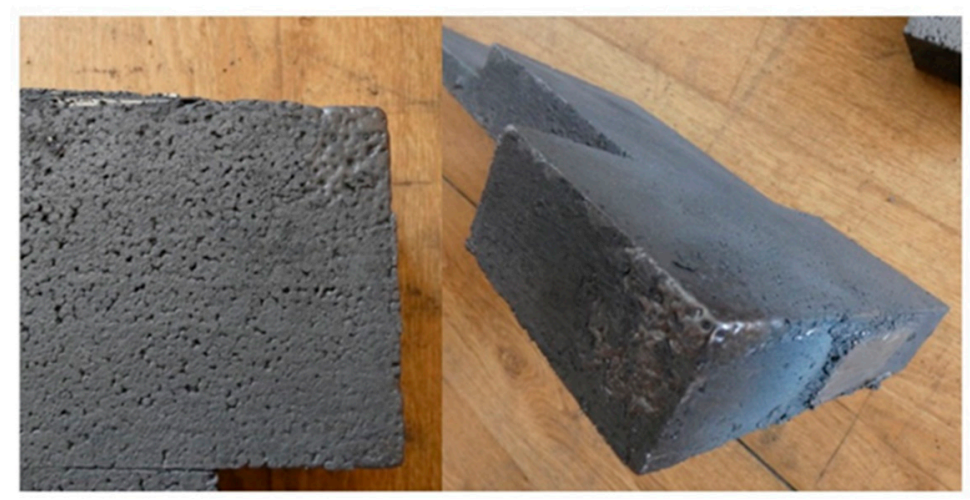

Figure 8. View of the surface where the lustrous carbon defect occurred; Melt 4.

The process of defect generation in the form of lustrous carbon has such a complex course that it is hard to record all the parameters affecting its formation. The studies performed resulted in selecting such factors that stimulate the occurrence of this defect and also their possible combinations.

Figure 9 presents an SEM photo of the lustrous carbon defects located near the top rough surface of the casting. It is apparent that the defect marked with 1 seems to open itself to the surface of the casting; it may seem like a crack; nevertheless, it was formed during the turbulent filling, when the carburized casting skin wrinkled. On the right-hand side of this defect, there is another that, at first glance, seems to be separated from the surface; nevertheless, a closer examination allows us to find that its edges connect at its top and adopt the form of a double film opening up at the surface. The degenerated morphology of the graphite precipitations near the defects, similar to the degeneration near the rough surface, supports this hypothesis as the defects entrained previously constituted a part of the casting surface being formed. 


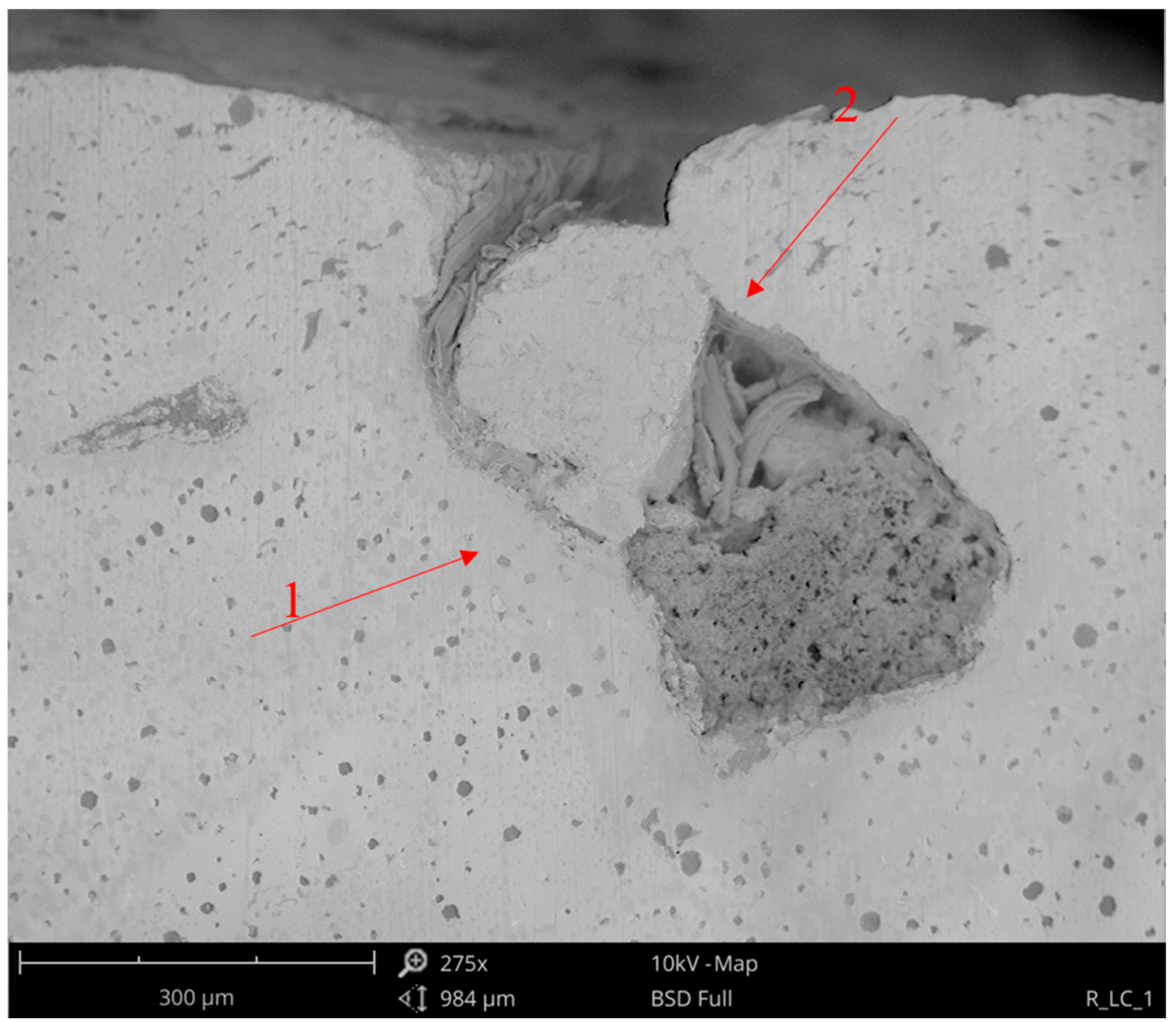

Figure 9. Carbon bifilms near the surface of the casting, SEM; Melt 2.

The results of EDS analysis performed on the surface of inclusion presented in Figure 9 are shown in Figure 10. It can be seen that a high concentration of carbon allows us to find that the inclusion consists mainly of carbon. The presence of Fe can result from the fact that EDS also scanned the volume located below the carbon layer. The presence of oxygen can be explained with Campbell's theory [5], indicating that between the layer of carbon and the alloy, a thin oxide layer can be formed. A high concentration of $\mathrm{Cl}$ is connected with the fact that the sample was etched using iron chloride still present despite the thorough rinsing of the sample. This unfortunate issue allowed for the formulation of a vital conclusion that the presence of such defects may cause the retention of liquids in their center, which may act as a dangerous corrosion starting point. It is also possible that the undesirable capillary intake of liquids into the inclusion may occur.
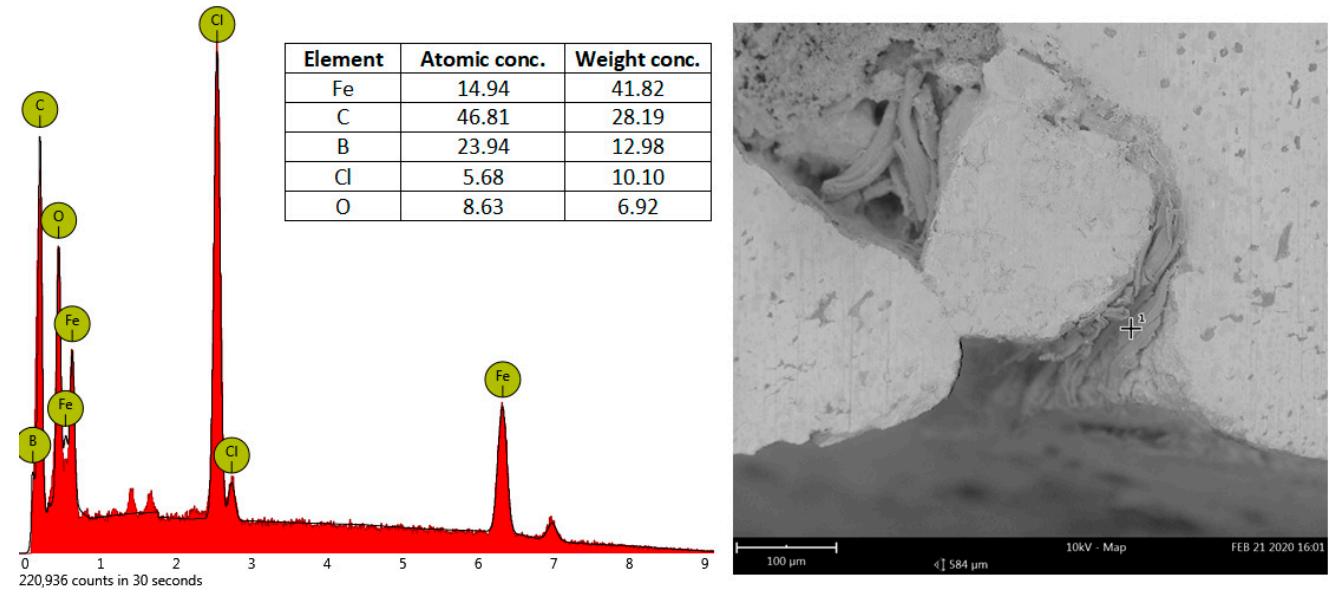

Figure 10. EDS analysis of the defect surface, SEM EDS; Melt 2. 
A magnified image of the defect surface marked with 1 presented in Figure 9 is shown in Figure 11. It can be seen that the carbon film constituting the defect surface is slightly separated from the metal surface. According to Campbell [9], due to the differences in the thermal expansion of the carbon film and iron during the crystallization of casting, the carbon film may detach from the casting. In the upper left corner of the figure, a large number of cracks resembling inclusion are present. They are also believed to be associated with the turbulence, as they are connected to the larger defect and can simply be its folded extension.

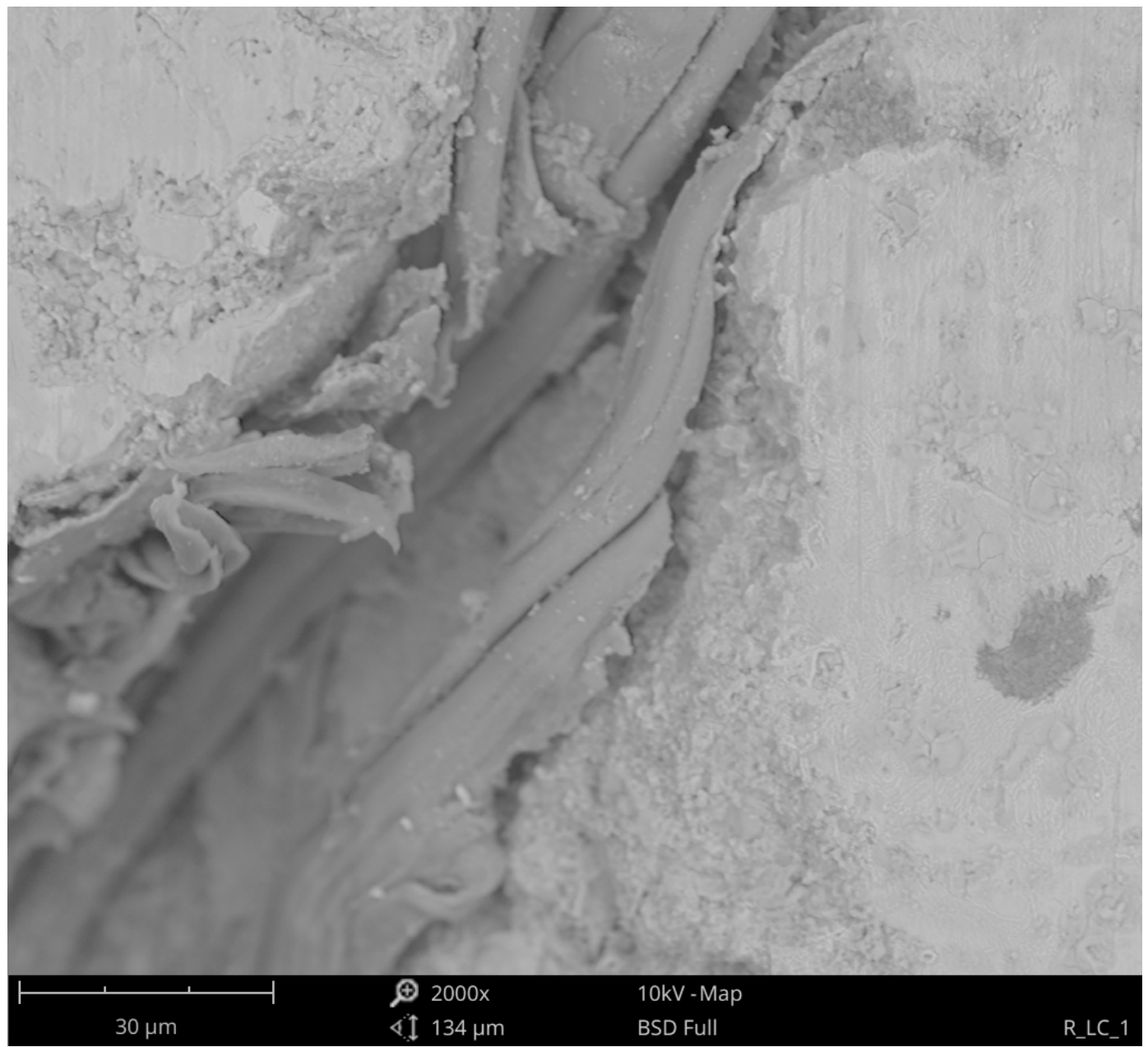

Figure 11. Magnification of a carbon bifilm, SEM; Melt 2.

Typical castings manufactured with an unoptimized gating system that allows for breaking wave formation contain a significant amount of such carbon bifilm inclusions. The majority of them are connected with the casting rough surface. Interestingly, the length of such bifilms can reach up to centimeters! Figure 12, on the left-hand side, presents the surface outlet of the bifilm or rather its inlet; on the right-hand side, the end of the bifilm is shown; the authors would like to draw the readers' attention to the complexity of the inclusion with numerous folds. It should be kept in mind that the presence of such inclusions severely impairs the mechanical properties of manufactured castings, as they act as large internal cracks. Additionally, because there is a space between the two films composing the bifilm, such a defect can form a potential leak path [21,22], resulting in a lack of casting tightness. 


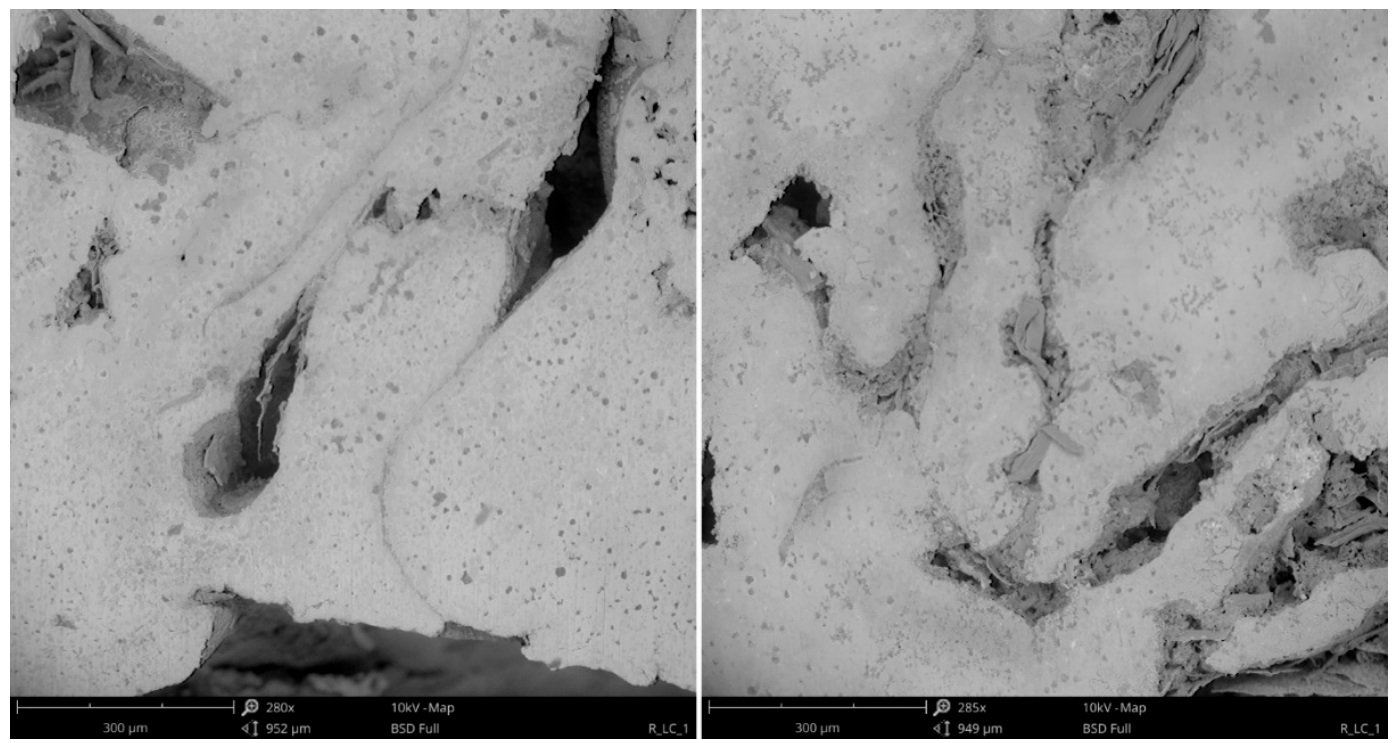

Figure 12. Carbon bifilm inclusions, SEM; Melt 2.

Particularly interesting images of entrained carbon bifilms can be obtained by using a stereomicroscope (SM), allowing us to present the character and morphology of the defect at the casting's rough surface. It can also be used to highlight the defects. Figure 13 presents two entrained films from the manufactured test castings; a corroded rough surface is visible at the top of each image. On the left-hand side, Figure 13 presents two entrained bifilms with a tangled end, potentially creating a large defect. If the surface of the casting was subjected to machining, the furled part could be uncovered. On the right-hand side, Figure 13 presents a visible triple fold in the rough surface with a section showing the entrained part of the film.
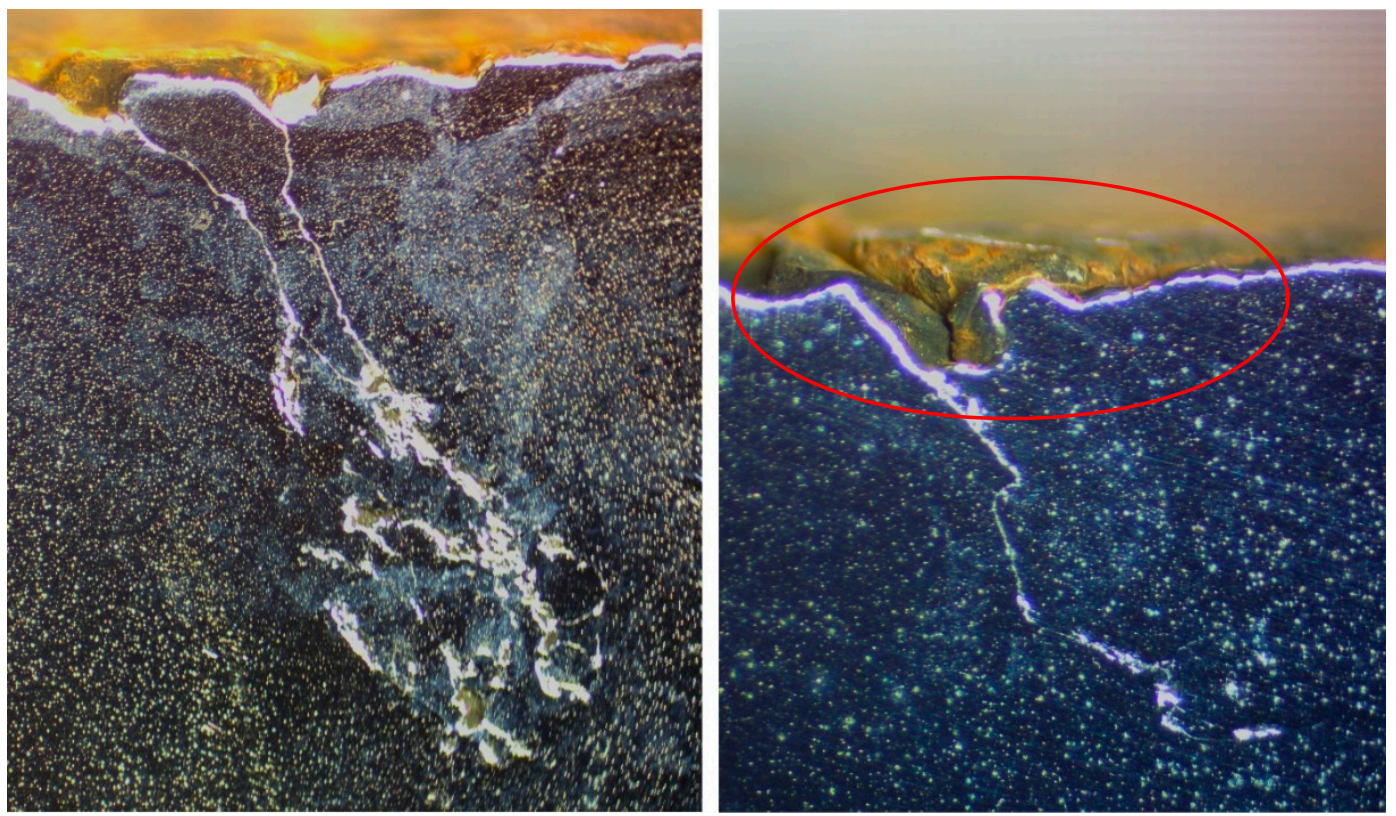

Figure 13. Entrained carbon bifilms near the casting's rough surface, stereomicroscopy; Melt 2.

The analysis of entrained films presented in Figure 14 using light microscopy (LM) at a magnification of $x 50$ on unetched samples allowed us to confirm their double nature and show that there is a possibility that, in other sections, such defects could be misinterpreted as porosity. 

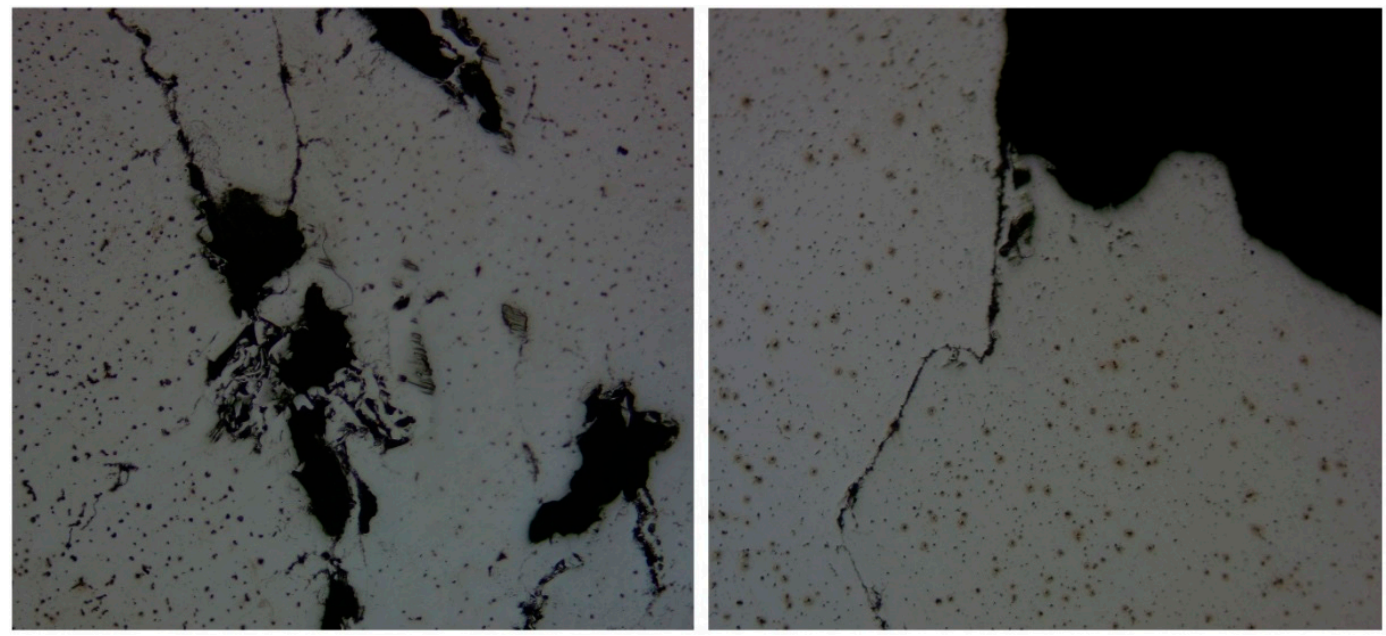

Figure 14. Magnification of entrained bifilms, light microscopy (LM) (x50); Melt 2.

The analysis of the sample etched with iron chloride allowed us to find that, in the vicinity of the carbon film, the matrix exhibits decarburization features, as shown in Figure 15. Figure 15, on the left-hand side, presents the stereomicroscope image of the inclusion featuring a visible light-colored zone near the film, as well as the surface. It can be seen that the matrix changes from pearlite to ferrite in the zone adjacent to the film. On the right-hand side, the LM image at a magnification of x50 is presented to show that for other entrained films, the trend is the same. Similar phenomena found near the presented films and the surface allow us to emphasize the fact that entrained defects previously constituted a part of casting surface being formed.
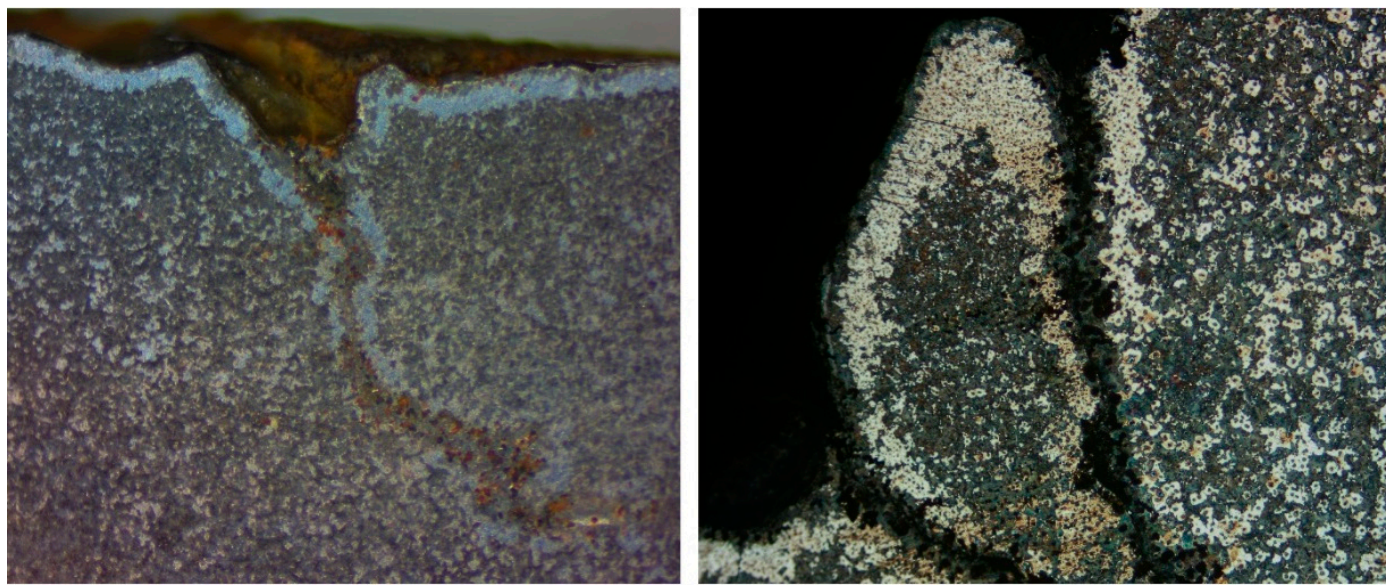

Figure 15. Stereomicroscope (SM) image of a carbon bifilm on the left; LM image of a carbon bifilm on the right (x50); Melt 2.

The carbon bifilm entrainment shown can be eliminated by observing a strict process regime in the foundry. Special attention should be paid to the pouring temperature and gating system design to help prevent turbulence.

\section{Discussion}

The performed studies should be analyzed by bearing in mind that the majority of the casting patterns and cast iron sample products based on them presented in this paper do not reflect the sizes of the Rafamet foundry products. The products of the foundry are much larger, reaching sizes of several meters. However, the shapes and sizes of the patterns have been designed to simulate the reasons for defects in production castings. 
Four temperatures, ranging from 1236 to $1360^{\circ} \mathrm{C}$, were used in the performed studies. For the two lowest temperatures, i.e., 1236 and $1250{ }^{\circ} \mathrm{C}$, the lustrous carbon defects were detected. The quality of those castings was significantly different from the assumed one. The edges were represented imperfectly. That was due to the cast iron flowing power being insufficient in this temperature range. The metal capacity was not sufficient to fill all the mold cavity spaces.

For the highest temperatures of 1305 and $1360{ }^{\circ} \mathrm{C}$, no defects similar to those found in the castings filled at lower temperatures were detected. On the other hand, in this case, numerous burns of mold compounds were detected. This was of special importance while forming the pattern in the molding compound that used 100\% reclaim sand and showed much higher fine fraction contamination after reclamation, which multiplied the surface area of the burns. This problem can be solved by adding a certain amount of fresh sand or by using reclaim sand without dusty fraction contamination (effective dedusting of reclaim). The proportion of fresh sand to the reclaimed sand of 1:9 during the studies allowed us to obtain surfaces free from burns. This result was observed while analyzing the melt series 1.

The significantly variable chemical composition in the cast iron experiments depended on the length of the testing period. Each of the four melt series used different scrap batches. Each of them was analyzed for chemical composition and accepted for production based on this. This is extremely important to obtain an optimum chemical composition under such conditions, even if it is not the best one. Alloy additions in the charge generally improve the mechanical properties; however, some of them-e.g., boron — can harm the ductile cast iron's structure, degenerating the spheroidal graphite inclusions.

The impact of selected elements on the type of cast structure depends on many factors, first of all, on the concentration of the remaining elements, because this effect can frequently be synergistic. The contradictory conclusions obtained show a complex mechanism for the effects of the cast iron's chemical composition on its final structure and properties.

The studies presented allowed us to define which parameter has the largest effect on the generation of lustrous carbon defects. This parameter, the pouring temperature, is also one of the key parameters used to analyze defects such as misruns or rattails (folds). The temperature value is closely related to the flowing power of the liquid cast iron. By contrast, this is mainly affected by chemical composition, which was significantly variable in the studies performed for each melt series. The chemical composition determines, among other things, the liquidus temperature. With an increase in eutectic Sc saturation, at the same chemical composition, the flowing power increases as the degree of cast iron overheating rises. The best flowing power produces alloys whose carbon equivalent is close to the eutectic point $(\mathrm{Sc}=1)$.

In the performed studies, the cast iron from melt batch No. 3 had the composition most similar to the eutectic point. This cast iron filled the casting mold most effectively, thus accurately reflecting the pattern, which resulted from a high flowing power induced by the chemical composition and high pouring temperature. This remains the state of the art, which shows that the most important factors affecting the cast iron flowing power include the chemical composition, overheat level, and pouring temperature, i.e., the temperature of the alloy during the filling of the mold cavity.

Elements such as carbon, phosphorus, and silicon have the highest effects on the flowing power. An increased concentration of manganese also improves the flowing power. The amount of sulfur does not have a significant impact on this parameter, because the concentration of sulfur for ductile cast iron should be reduced as much as possible.

Modified cast iron shows a higher trend for the creation of contraction cavities, shrinkage porosities, shrinkage depressions, and lustrous carbon defects. It is very important to properly design the inlet and feed system. It is necessary to monitor the state of the liquid metal. Process tests, including the ones presented in this paper, allow us to determine the parameters stimulating the defects. High-quality castings need a very good adjustment of the lost-foam casting (LFC) process to the production conditions. 


\section{Conclusions}

This article focuses on the so-called lustrous carbon defect and its appearance on the cast iron castings produced by the full-mold technology in industrial conditions. A number of experiments have been carried out to find how the most important technological parameters influence this phenomenon. From the analysis of the results have been drawn the following general conclusions:

The lustrous carbon defect has a complex nature, and it is almost impossible to determine and understand its full origin in real industrial conditions, as suggested by the presented research.

Among others, the pouring temperature seems to be one of the key parameters used to analyze such defects as well as misruns or rattails (folds), which accompany the lustrous carbon defects quite often. The chemical composition of the iron does influence this defect occurrence, too, but in industrial conditions, it is hard to analyze and control.

The LC defects can often be misinterpreted as other types of imperfections; thus, effort may be put into the wrong part of the manufacturing process.

The contact zone between the foam pattern and the molten iron flowing into the mold is another important point to focus on, but again, too many factors affect it to make it possible to control its behavior.

Author Contributions: Conceptualization, M.J. and R.D.; investigation, M.J.; methodology, J.J., M.J., and R.D.; resources, R.D.; supervision, J.J. and R.D.; writing—original draft, J.J. and M.J.; writing—review and editing, J.J. All authors have read and agreed to the published version of the manuscript.

Funding: This publication was financed by the statutory subsidy of the Faculty of Mechanical Engineering of the Silesian University of Technology in 2019.

Conflicts of Interest: The authors declare no conflict of interest.

\section{References}

1. Shroyer, H.F. Cavityless Casting Mold and Method of Making Same. U.S. Patent No. 2,830,343, 15 April 1958.

2. Mocek, J.; Zych, J.; Krubnik, Ł. Casting of Al-Si alloys in the full-mold technology. Process conditions. Metall. Foundry Eng. 2014, 40, 161-174. [CrossRef]

3. Pacyniak, T. Metoda Pełnej Formy. Wybrane Aspekty; Monografie Politechniki Łódzkiej: Łódź, Poland, 2013.

4. Soiński, M.; Kordas, P.; Skurka, K. Trends in the Production of Castings in the World and in Poland in the XXI Century. Arch. Foundry Eng. 2016, 16, 5-10. [CrossRef]

5. Campbell, J. Complete Casting Handbook, 2nd ed.; Butterworth-Heinemann: Oxford, UK, 2015.

6. Khodai, M.; Mirbagheri, S.M.H. Behavior of Generated Gas in Lost Foam Casting. Int. J. Mater. Metall. Eng. 2011, 5, 151-155.

7. Mocek, J.; Chojecki, A. Gas atmosphere formed in casting by full mold process. Arch. Metall. Mater. 2014, 59, 1045-1049. [CrossRef]

8. Żuk, M.; Górka, J.; Czupryński, A.; Dojka, R. Repair Welding of Cast Iron Coated Electrodes. In Materials Science and Engineering, Proceedings of the Modern Technologies in Industrial Engineering ModTech, Sibiu, Romania, 14-17 June 2017; IOP Conference Series; IOP Publishing: Bristol, UK, 2017; Volume 227, pp. 1757-8981.

9. Campbell, J.; Naro, R.L. Lustrous carbon on gray iron. In AFS Proceedings; American Foundry Society: Schaumburg, IL, USA, 2010; pp. 1-6.

10. Żmudzińska, M.; Faber, J.; Perszewska, K.; Źółkiewicz, Z.; Maniowski, Z. Studying the emission of products formed during evaporation of polystyrene patterns in the lost foam process in terms of the work environment. Prace Instytutu Odlewnictwa 2011, 23-33. [CrossRef]

11. Griffiths, W.D.; Ainsworth, M.J. Instability of the Liquid Metal-Pattern Interface in the Lost Foam Casting of Aluminum Alloys. Metall. Mater. Trans. A 2016, 47, 3137-3149. [CrossRef]

12. Campbell, J.A. Hypothesis for Cast Iron Microstructures. Metall. Mater. Trans. B 2009, 40B, $786-801$. [CrossRef]

13. Chakherlou, T.N.; Mahdinia, Y.V.; Akbari, A. Influence of lustrous carbon defects on the fatigue life of ductile iron castings using lost foam process. Mater. Des. 2011, 32, 162-169. [CrossRef] 
14. Naro, R.L. Formation and control of Lustrous Carbon Surface Defects in iron and steel castings. Am Foundry Soc. Trans. 2002, 110, 815-834.

15. Kaliuzhnyi, P. Influence of Sand Fluidization on Structure and Properties of Aluminum Lost Foam Casting. Arch. Foundry Eng. 2020, 1, 122-126.

16. Mirbagheri, S.M.H.; Serajzadeh, S.; Varahram, N.; Davami, P. Patterning of foam degradation in lost foam casting process. Mater. Des. 2006, 27, 115-124. [CrossRef]

17. Azimi, H.R.; Rezaei, M.; Abbasi, F. Thermo-oxidative degradation of MMA-St copolymer and EPS lost foams: Kinetics study. Thermochim. Acta 2009, 488, 43-48. [CrossRef]

18. Shayegh, J.; Hossainpour, S.; Rezaei, M.; Charchi, A. Developing a new 2D pattern for heat transfer and foam degradation in EPS lost foamcasting (LFC) process. Int. Commun. Heat Mass. Transf. 2010, 37, 1396-1402. [CrossRef]

19. Liu, X.J.; Bhavnani, S.H.; Overfelt, R.A. Simulation of EPS foam decomposition in the lost foam casting process. J. Mater. Process. Tech. 2007, 182, 333-342. [CrossRef]

20. Pacyniak, T.; Kaczorowski, R. Badanie własności pokryć ogniotrwałych nanoszonych na patterne polistyrenowe, stosowane przy wytwarzaniu odlewów metodą lostfoam. Arch. Foundry 2003, 3, 147-156.

21. Campbell, J. Leakage Defects via Bubble Trails in Grey Iron Castings. Int. J. Met. 2007, 1, 7-16. [CrossRef]

22. Naro, R.L. Battling the Elusive Lustrous Carbon Defect. Mod. Cast. 2003, 5, 32-35.

(C) 2020 by the authors. Licensee MDPI, Basel, Switzerland. This article is an open access article distributed under the terms and conditions of the Creative Commons Attribution (CC BY) license (http://creativecommons.org/licenses/by/4.0/). 